\title{
Acute, Multiple-Dose Dermal and Genetic Toxicity of Nu-3: A Novel Antimicrobial Agent
}

\author{
Juan Sun, ${ }^{1}$ Yanxin Hu, ${ }^{1}$ Shanping Cao, ${ }^{1}$ Guozhong Zhang, ${ }^{1}$ Lun-Quan Sun, ${ }^{2,3}$ \\ and Ming Wang 1 \\ ${ }^{1}$ College of Veterinary Medicine, China Agricultura University, Beijing 100193, China \\ ${ }^{2}$ Department of Medical and Molecular Biosciences, University of Technology Sydney, Broadway, Sydney, NSW 2007, Australia \\ ${ }^{3}$ Xiangya Hospital, Center for Molecular Medicine of Central South University, Changsha 410078, China
}

Correspondence should be addressed to Lun-Quan Sun, lun-quan.sun@uts.edu.au and Ming Wang, vetdean@cau.edu.cn

Received 26 January 2010; Revised 10 May 2010; Accepted 9 June 2010

Academic Editor: Schwan William

Copyright (c) 2010 Juan Sun et al. This is an open access article distributed under the Creative Commons Attribution License, which permits unrestricted use, distribution, and reproduction in any medium, provided the original work is properly cited.

\begin{abstract}
Nu-3 [butyl-phosphate-5' -thymidine- $3^{\prime}$-phosphate-butyl] is a modified nucleotide that has been shown to have antimicrobial activity against a range of bacteria including Pseudomonas aeruginosa. However, data on the toxicological profile of Nu-3 are still lacking. In the present study, the toxicity of Nu-3 was evaluated by the following studies: acute oral toxicity, dermal and mucous membrane irritation, multiple-dose toxicity and genotoxicity in vivo and vitro. The acute oral toxicity test in mice showed that Nu$3 \mathrm{had}$ an $\mathrm{LD}_{50}$ of $2001 \mathrm{mg} / \mathrm{kg}$ body weight. The irritation tests on rats revealed that $\mathrm{Nu}-3$ was not irritant, with an irritation scoring of 0 . The multiple-dose toxicity study in rats showed that Nu-3 did not cause significant changes in histology, selected serum chemistry, and hematological parameters compared to the controls. Rats administrated with multiple-doses of Nu-3 showed no visible toxic symptoms. Both in vitro and in vivo, $\mathrm{Nu}-3$ exhibited no notable genetic toxicity. Overall, the data suggest that $\mathrm{Nu}-$ 3 is hypotoxic or nontoxic antimicrobial compound that warrants being further developed for treating Pseudomonas aeruginosa infection.
\end{abstract}

\section{Introduction}

Pseudomonas aeruginosa has become the most common gram-negative bacterial species associated with serious hospital-acquired infections $[1,2]$. Mortality rates outbreaks from $P$. aeruginosa in burn units can be significantly high (60\%) [3]. Immediate use of effective antimicrobial therapy for $P$. aeruginosa bacteremia has been shown to significantly reduce mortality [4]. However, the intrinsic resistance of $P$. aeruginosa to many antimicrobial agents and, in addition, the variety of their increasingly recognized acquired resistance mechanisms make their management in the hospital setting problematic [5]. Of great concern is the growing emergence of multidrug-resistant (MDR) strains of P. aeruginosa [69], and the severity of associated infections. Unfortunately, the development of new antibiotics with activity against gram-negative organisms has not kept pace with the increase in prevalence of multidrug resistant pathogens. To provide clinicians with credible alternative treatments to reduce the increasing human mortality and morbidity associated with the infectious diseases by drug-resistant bacterial pathogens, there is a compelling need to develop new therapeutic agents that are effective against drug-resistant mutants [10].

Nubiotics are a novel class of modified nucleotides-based antimicrobial agents. Structurally, nubiotics are synthetic nucleotides and oligonucleotides with nuclease-resistant backbones, and are fully protonated. Although the exact mechanisms of antibiotic actions for nubiotics are not totally understood, they are thought to be indeed different from that of the traditional antimicrobial drugs and the protonated structures are believed, in part, to make nubiotics to be taken up by bacterial cells more easily. As a family, nubiotics has many members, including $\mathrm{Nu}-2, \mathrm{Nu}-3, \mathrm{Nu}-4$, and $\mathrm{Nu}-5$, which have been shown to have effective therapeutic effect in the burn wound Pseudomonas aeruginosa infection model established in mice [11]. 
Nu-3 [butyl-phosphate- $5^{\prime}$-thymidine- $3^{\prime}$-phosphatebutyl] is a potent nubiotics that is a fully protonated deoxynucleotide. The chemical structure of Nu-3 is shown in Figure 1. The therapeutic efficacy of $\mathrm{Nu}-3$ against pulmonary Pseudomonas aeruginosa infection was evaluated in vivo animal model [11], in which liposome-encapsulated $\mathrm{Nu}-3$ presented efficacious antibacterial activity.

To further assess Nu-3 as a potential new antibiotic for topical uses, we performed studies for its acute, multipledose dermal toxicity and the irritation to skin and eyes and genetic toxicity. These studies have revealed that $\mathrm{Nu}-3$ has hypotoxicity at high dosage, and it has no chronic toxicity and irritation. It was also revealed that $\mathrm{Nu}-3$ does not have notable genetic toxicity. This study provides solid data to warrant further development of Nubiotics as a novel class of antimicrobial agents for treating Pseudomonas aeruginosa infection.

\section{Materials and methods}

2.1. $\mathrm{Nu}-3$. Nu-3 was synthesized and purified at Oligos and so forth, Inc. (Oregon) with $99.5 \%$ purity (HPLC).

2.2. Animals. Balb/c mice and Sprague-Dawley rats used in this study were purchased from Beijing Vital River Company. The body weight ranged from $17-20 \mathrm{~g}$ for mice and $250-300 \mathrm{~g}$ for rats. All the test animals were randomized into groups after being quarantined for 3-5 days before experiments. Randomly, the body weight variation was within $\pm 20 \%$ of the mean weight in each sex. The animals were housed in stainless mouse cages with sterile padding. Food and water were aseptic and available adlibitum. All the mice and rats were housed in a room with a temperature of $20-25^{\circ} \mathrm{C}$, a relative humidity of $40 \%-70 \%$, and a 12 -hourlight/dark cycle. The use and care of the animals followed the Regulations for the Administration of Affairs Concerning Experimental Animals in China (11-14-1988).

2.3. Cells and Culture. Chinese hamster ovary cells ( $\mathrm{CHO}$ and $\mathrm{CHO}-\mathrm{K}_{1}$ ) were purchased from Cell Culture Center, Peking Union Medical University. $\mathrm{CHO}-\mathrm{K}_{1}$ cells were grown in DMEM/F-12 supplemented with $10 \%$ fetal bovine serum (FBS), $2 \mathrm{mM}$ L-glutamine, and penicillin-streptomycin ( 100 units $/ \mathrm{ml}, 100 \mu \mathrm{g} / \mathrm{ml})$. Incubation was performed at $37^{\circ} \mathrm{C}$ in a humidified atmosphere of $5 \% \mathrm{CO}_{2}$ in air.

2.4. Intragastric Acute Toxicity Study in Mice. There were five male and five female mice per dose group. Mice were intragastrically administered with a total dose of 2500 , $1988,1580,1256$, and $1000 \mathrm{mg} / \mathrm{kg} / \mathrm{mouse}$ of $\mathrm{Nu}-3$ in saline (Table 1). The dosing volumes were all $0.5 \mathrm{ml} /$ mouse. A control group received saline only. All the mice were intragastrically administered with one dose. Mice were fasted $24 \mathrm{~h}$ before given the test materials and were allowed to get food and water adlibitum after intragastric administration. Animals were observed for their death and subjected to a gross necropsy immediately after they died until day 8 , after which the survivor were euthanized and subjected to a gross necropsy and histopathology observation for toxicity. Livers were removed and fixed by $4 \%$ neutral formalin at room temperature for $48 \mathrm{~h}$. The serial tissue sections at $5-\mu \mathrm{m}$-thick were obtained after embedded in paraffin. Each slide was stained with hematoxylin and eosin (H\&E) then examined under light microscopy (Olympus CX31). Throughout the study, the clinical symptoms, neurological behavior and body weight were recorded daily.

2.5. T-Cell Proliferation Study in Mice after Being IntragastricTreated with $\mathrm{Nu}-3$. Three mice of control, male and female group were sacrificed and their lymphocyte suspensions were prepared from the spleen on $24 \mathrm{~h}$ after being intragastrically administered with a single dose of $\mathrm{Nu}-3$ at $100 \mathrm{mg} / \mathrm{kg} /$ mouse. Single-lymphocyte suspensions were incubated in triplicates in 96-well plates at $2 \times 10^{5}$ cells/well, in RPMI-1640 plus 5\% of fetal calf serum (FCS) at $37^{\circ} \mathrm{C}$ in a $5 \% \mathrm{CO}_{2}$ incubator and stimulated for $48 \mathrm{~h}$ with $2 \mu \mathrm{g} / \mathrm{ml}$ precoated anti-CD3 and $1 \mu \mathrm{g} / \mathrm{ml}$ anti-CD28 (positive control), $2 \mu \mathrm{g} / \mathrm{ml}$ of BSA (irrelevant antigen), or no antigen (negative control). T-cell proliferation was evaluated by Cell Titer 96 Aqueous Nonradioactive Cell Proliferation Assay was performed according to the manufacturer's instruction (Promega, USA). The mixture of MTS/PMS ( $20 \mu \mathrm{l}$ each well) was added to each well to develop the color. After $4 \mathrm{~h}$ of incubation, the OD values of plates were read at $490 \mathrm{~nm}$ by a plate reader (Magellan, Tecan Austria GmbH). Data were expressed as stimulation index (SI), calculated as the mean reading of triplicate wells of antigen stimulation, and divided by the mean reading of triplicate wells of negative control.

2.6. Twenty-Eight-Day Dermal Toxicity Study in Rats. There were ten rats in the treatment group ( 5 males; 5 females) in which rats were treated with $50 \mu \mathrm{l}$ of $100 \mathrm{mg} / \mathrm{ml} \mathrm{Nu}-3$ in saline. The control group containing same number of rats received saline only. Fur was clipped from dorsal area of the trunk $24 \mathrm{~h}$ prior to the test and was reclipped as necessary to allow observation and dosing. The test materials were applied on the shaved area and kept in contact with the help of nonirritating styptic plaster and porous gauze bandage. To ensure that local application of $\mathrm{Nu}-3$ remained in the dorsum of animals, the measure of fastening multiply was taken. Briefly, a band-aid was put on the liniment area, and then covered a pad of medical gauze, followed by wrapping up with gauze bandage. Rats were treated with the test materials for $6 \mathrm{~h}$ per day. At the end of 6 hours, any residual material was gently removed from the treatment site using cotton bud soaked in distilled water. Animals were treated in the way described above everyday for 28 days. Cage side observation was made daily, which included evaluation of the effect on skin, fur, eyes, and respiratory and neural behavior. By the 29th day half of the rats were euthanized and subjected to a gross necropsy. Organs were taken out carefully and weighted. The remaining animals were observed for further 14 days, and then they were euthanized, subjected to a gross necropsy and organ weights recorded on day 43. During the study, body weight, water and food consumption were monitored according to the experimental design. Blood 


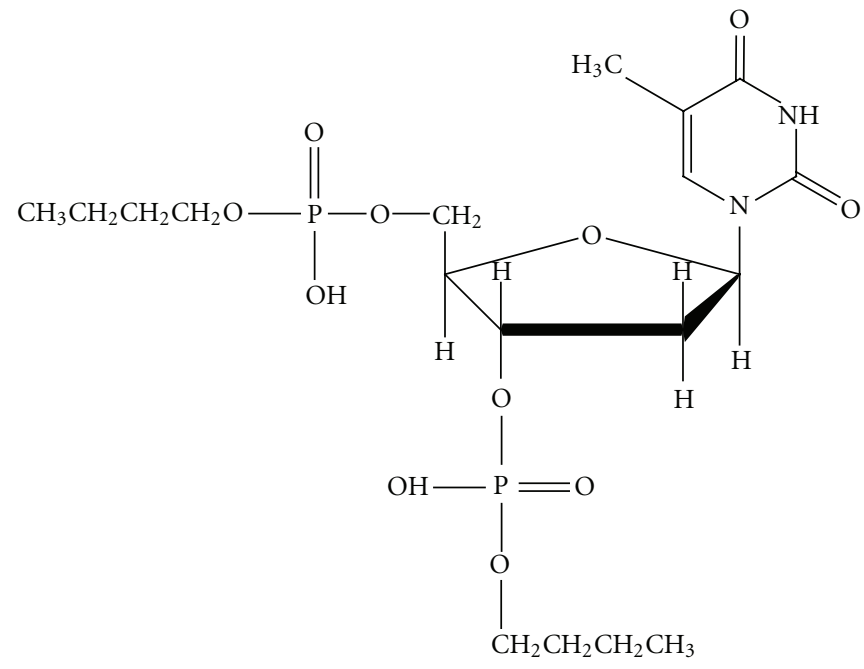

Figure 1: Chemical structure of Nu-3.

TABLE 1: Dosing table for acute intragastric toxicity study of $\mathrm{Nu}-3$ in mice.

\begin{tabular}{|c|c|c|c|c|c|c|}
\hline \multirow{2}{*}{ Groups } & \multirow{2}{*}{ Treatment } & \multirow{2}{*}{$\begin{array}{c}\text { Dose* } \\
(\mathrm{mg} / \mathrm{kg})\end{array}$} & \multirow{2}{*}{$\begin{array}{c}\text { Drug conc. } \\
(\mathrm{mg} / \mathrm{ml})\end{array}$} & \multirow{2}{*}{$\begin{array}{l}\text { Dose vol. } \\
\text { (ml/mice) }\end{array}$} & \multicolumn{2}{|c|}{ No. of animals } \\
\hline & & & & & Male & Female \\
\hline 1 & $\mathrm{Nu}-3$ & 2500 & 87.35 & 0.5 & 5 & 5 \\
\hline 2 & $\mathrm{Nu}-3$ & 1988 & 70.91 & 0.5 & 5 & 5 \\
\hline 3 & $\mathrm{Nu}-3$ & 1580 & 56.35 & 0.5 & 5 & 5 \\
\hline 4 & $\mathrm{Nu}-3$ & 1256 & 44.95 & 0.5 & 5 & 5 \\
\hline 5 & $\mathrm{Nu}-3$ & 1000 & 34.39 & 0.5 & 5 & 5 \\
\hline
\end{tabular}

*Balb/c mice were intragastrically administered with a single dose of $2500,1988,1580,1256,1000 \mathrm{mg} / \mathrm{kg} / \mathrm{mouse}$ of Nu-3 in saline.

samples were collected from the caudal vein of all the rats weekly.

2.7. Rat Skin and Eye Irritation Test. Ten rats were used in the test. On the day prior to dosing, an area on the dorsal surface of the skin was clipped free of hair. On the day of dosing, the clipped areas in rats were lacerated to errhysis with sterile pinheads. Then $10 \mathrm{mg} / \mathrm{ml} \mathrm{Nu}-3$ in saline was applied to the shaved area of five rats and the skin was covered with nonirritating styptic plaster and porous gauze bandage. The rats were then returned to their cages. After $6 \mathrm{~h}$ of exposure period, the coverings were removed and the test area was rinsed with distilled water. The other five rats were used as control and treated with saline. The rats were examined for the presence of erythema and oedema according to a skin irritation scoring standard at the intervals of $1,24,48$, and $72 \mathrm{~h}[12]$.

Rat eye irritation test was used to evaluate the degree to the mucous irritation of $\mathrm{Nu}-3$. Six rats were used for this test and each animal served as its own control. $0.03 \mathrm{ml}$ $\mathrm{Nu}-3$ of $1 \mathrm{mg} / \mathrm{ml}$ concentration with saline was dripped to the left eyes of the rats, and $0.03 \mathrm{ml}$ saline was dripped to the right eyes of the rats as control. All the measures were taken to ensure that the test materials are dripped into the conjunctival sac of the rats. The rats were examined for the presence of changes in eyes according to the eye irritation scoring standard at grading intervals of $1,4,24,48,72$ and
$96 \mathrm{~h}$. Then sum of scores calculated was classified according to the eye irritation scoring standard [12].

2.8. In Vitro CHO/HGPRT Mammalian Cell Mutagenesis Assay. The purpose of this study was to assess the ability of $\mathrm{Nu}-3$ to induce mutations at the HGPRT locus in cultured mammalian cells. $\mathrm{CHO}-\mathrm{K}_{1}$ cells were used for this assay. Cultures were purged of preexisting mutants by growth for 2 days in DMEM/F-12 medium supplemented with $10 \%$ FBS, $5 \times 10^{-6} \mathrm{M}$ thymidine, $1 \times 10^{-5} \mathrm{M}$ hypoxanthine, and $3.2 \times 10^{-6} \mathrm{M}$ aminopterin. The test was performed according to the procedure of O'Neill and Hsie [13] and O'Neill et al. $[14,15]$. The cells which were purged of preexisting mutants were treated for $4 \mathrm{~h}$ with the test and control materials and then allowed an expression time of 7-9 days; the cells were then replated. After the period of expression of the mutant phenotype, mutant colonies were selected in the following manner. Each culture flask was trypsinized and the cells were seeded in new flasks as follows: (a) 3 flasks each with 200 cells and without the purine analogue 6-thioguanine; (b) 3 flasks each with $2 \times 10^{5}$ cells and with 6-thioguanine $(10 \mu \mathrm{g} / \mathrm{ml})$. After 8 days, selection was determined by the formation of colonies resistant to the purine analogue. Next, the colonies were fixed with methanol for $15 \mathrm{~min}$ and stained with Giemsa (Sigma) for $30 \mathrm{~min}$. Giemsa was poured off and visible colonies were counted. $\mathrm{Nu}-3$ was evaluated in the presence and absence of a metabolic activation system 
derived from rat liver (S9). Dimethylbenzanthracene was used in the positive control for the activated assay and ethyl methanesulfonate was used in the positive control for the nonactivated assay. Saline was the negative control. The Nu-3 concentrations for the assay ranged from 500 to $2000 \mu \mathrm{g} / \mathrm{ml}$. The colony counts obtained were used to calculate: (a) cloning efficiency (CE) in absolute values (number of colonies formed divided by the number of cells seeded); (b) the number of mutant colonies observed in each treatment; (c) the absolute CE observed after selection; (d) the mutation frequency (MF) (number of mutant colonies divided by the number of clonable cells which was equal to the number of cells seeded $\times$ the absolute CE after selection).

2.9. In Vivo Mouse Micronucleus Assay. $\mathrm{Nu}-3$ was evaluated for its ability to induce micronuclei in the bone marrow of Balb/c mice according to Hayashi et al. [16]. Cyclophosphamide (PC) was used as the positive control, and saline was the negative control. Groups of five male and five female Balb/c mice were dosed with Nu-3 at 250, 500 , and $1000 \mathrm{mg} / \mathrm{kg}$ on 2 consecutive days via intragastric administration. All the mice were euthanized $6 \mathrm{~h}$ after the last dosing, and the bone marrow was taken to make smear. Bone marrow cells from animals were analyzed for the number of polychromatic erythrocytes (PCEs) that contained at least one micronucleus. A minimum of 2000 PCEs was analyzed for the negative control, the positive control and for mice treated with the Nu-3. The PCE fraction was determined by counting a minimum of 200 erythrocytes (PCEs plus normochromatic erythrocytes [NCEs]).

2.10. Statistical Analyses. Data were expressed as means $\pm \mathrm{SD}$ and subjected to one-way ANOVA with factors of treatment, genotype or wild type. Comparisons between two groups were performed by unpaired Student's $t$-test. A value of $P<.05$ was considered significantly different.

\section{Results}

3.1. Acute Oral Toxicity in Mice. Mice were intragastrically administered with a single dose of Nu-3 at 2500 (Group 1), 1988 (Group 2), 1580 (Group 3), 1256 (Group 4), and 1000 (Group 5) mg/kg/mouse (Table 1). Following the single dose, five male and four female mice in Group 1, four female in Group 2 died in 24 hours. One female in Group 2 and one female in Group 4 died on day 1. From day 2 to day 8 none of the mice in all the groups died. According to the mortality of each group, the minimum lethal dose (MLD) was calculated to be $1256 \mathrm{mg} / \mathrm{kg}$. Clinical observations of the dying mice attributed to the administration of $\mathrm{Nu}-3$ were lethargy, tachypnea, and tremor and disheveled clothing hair. The surviving mice did not show any evident toxic symptom in clinical observations. There were no treatmentrelated effects on mouse behavior in the cage and body weight for males or females (data not shown). In the early dead mice, some pathological changes were found, including livers turning white and brittle with some yellowish brown nidi, the change of the spleen surface into uneven with some hemorrhagic spots, and kidneys showing some gray-white focus on surfaces. It was also observed that there were some damages and hemorrhage in gastric walls and intestinal tracts of mice which died in 5 hours after being administered. There was no obvious pathological change at gross necropsy and histopathological changes in liver for scheduled euthanasia mice in the study (Figure 2).

3.2. T-cell Proliferation Study in Mice. To examine if the administration of $\mathrm{Nu}-3$ could affect on immune system, the spleen cells were used to test T-cell proliferation. As shown in Figure 3, the treatment with Nu-3 had no impact on proliferation of spleen T-cells stimulated with either anti-CD28 (positive control) or BSA (irrelevant antigen) compared with the cells from the nontreated mice. This data suggested that Nu-3 had no toxic effect on immune system.

3.3. Dermal Toxicity with 28-Day Repeated Doses in Rats. Rats were applied with $50 \mu \mathrm{l}$ of $100 \mathrm{mg} / \mathrm{ml} \mathrm{Nu}-3$ (total dose of $250 \mathrm{mg} / \mathrm{kg} /$ day) for 28 days. Cage side observation was made twice everyday. There were no evident toxic symptoms in both treated and control rats during observation time. Local dermal irritation was not observed in all test rats. Control and test rats showed a similar pattern of weight growth, food and water uptake (Figure 4). Although there seemed to be some lagging in water uptake in treated group compared to control (Figure 4(b)), the body weight of test group seemed to increase faster (Figure 4(a)). There were no treatmentrelated changes on food uptake in treated rats compared to the controls (Figure 4(c)). During the observation time after administrating Nu-3 on the back of the body for 28 days, there were no significant differences between the treated and control rats in the body weight gain although the treated rats took less water and food compared to the controls.

All rats survived until scheduled necropsy. Surviving animals were euthanized at day 29 and day 43. No obvious pathological changes were found in all organs by gross appearance. Moreover, there was no significant difference $(P>.05)$ in the organ weight between the test groups and the control group (Table 2).

The results of histopathological analysis of necropsy samples on liver, kidney, spleen and skin of the body back where $\mathrm{Nu}-3$ was applied showed no significant pathological changes and toxic effects except that there was a slight increase in skin labrocytes of the treated rats in comparison with the controls'. The microscopic examination revealed that liver, kidney, and spleen were normal.

Hematology and selected serum chemistry analyses also showed no significant differences $(P>.05)$ between control and treated groups (Table 3 ).

3.4. Skin and Eye Irritation in Rats. After applied with $\mathrm{Nu}-3$ on the dorsal surface, the rats were examined for the presence of erythema and oedema on the test area according to a skin irritation scoring standard [12]. The results showed that the scores for erythema and oedema were 0 at $1,24,48$, and $72 \mathrm{~h}$ after administration, which was the same to the controls'. The eye irritation scores were recorded according 


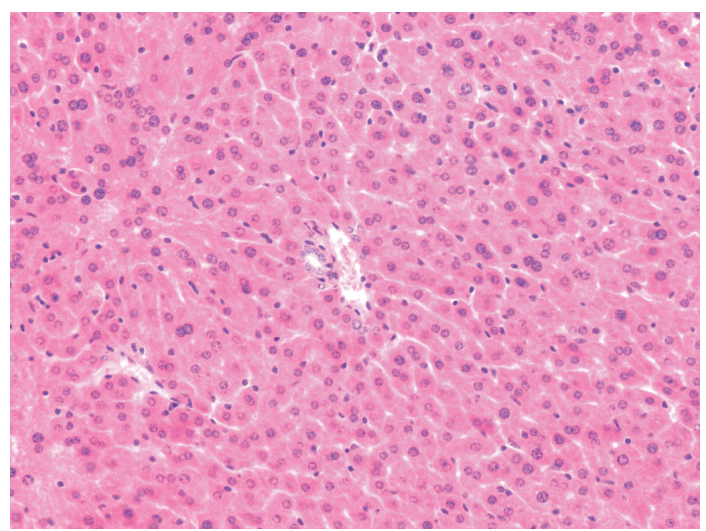

(a)

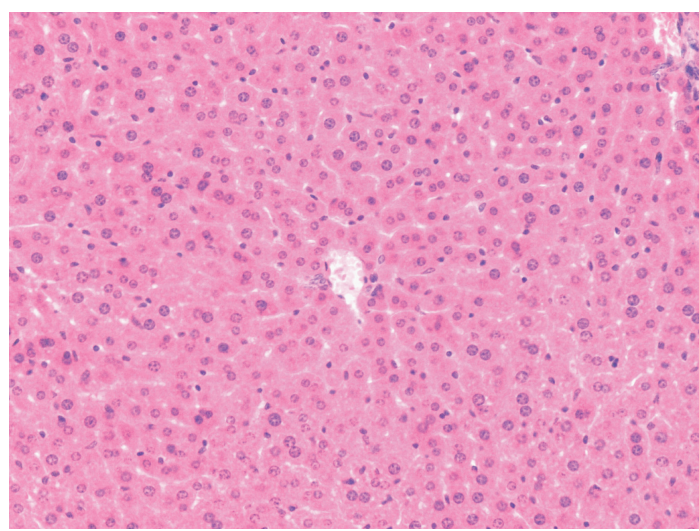

(b)

Figure 2: Histopathological observation of Nu-3 treated mice. (a) Livers from the control group. (b) Livers from the Nu1-3 treated group. The hepatic structure is normal no histopathological changes were observed. Original magnification $\times 400$.

TABLE 2: Absolute and relative organ weights of rats in 28-day dermal toxicity study of Nu-3.

\begin{tabular}{|c|c|c|c|c|}
\hline \multirow{2}{*}{ Organs } & \multicolumn{2}{|c|}{$\mathrm{Nu}-3^{*}$} & \multicolumn{2}{|c|}{ Saline } \\
\hline & Day 29 & Day 43 & Day 29 & Day 43 \\
\hline \multicolumn{5}{|l|}{ Liver } \\
\hline Absolute weight & $17.40 \pm 18.13$ & $16.33 \pm 13.14$ & $15.96 \pm 1.40$ & $18.73 \pm 0.57$ \\
\hline Relative weight* & $3.25 \pm 0.13$ & $3.45 \pm 0.17$ & $3.24 \pm 0.07$ & $4.17 \pm 0.16$ \\
\hline \multicolumn{5}{|l|}{ Spleen } \\
\hline Absolute weight & $0.70 \pm 0.03$ & $0.73 \pm 0.00$ & $0.73 \pm 0.00$ & $0.73 \pm 0.01$ \\
\hline Relative weight & $0.13 \pm 0.00$ & $0.16 \pm 0.00$ & $0.15 \pm 0.00$ & $0.16 \pm 0.00$ \\
\hline \multicolumn{5}{|l|}{ Kidney } \\
\hline Absolute weight & $3.43 \pm 0.50$ & $3.1 \pm 0.31$ & $3.20 \pm 0.12$ & $3.13 \pm 0.02$ \\
\hline Relative weight & $0.65 \pm 0.00$ & $0.66 \pm 0.00$ & $0.645 \pm 0.00$ & $0.70 \pm 0.00$ \\
\hline
\end{tabular}

* The concentration of Nu-3 was $100 \mathrm{mg} / \mathrm{ml}$. The relative weight was calculated as percentage of the organ to body weight. The data was expressed as average \pm SD.

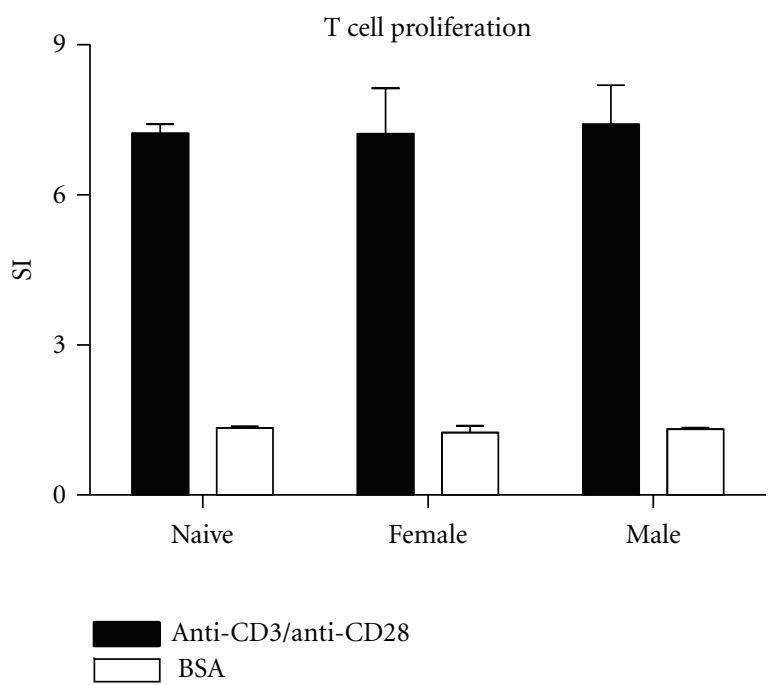

Figure 3: Analysis of T-cell proliferation in mice after being intragastric treatment with $\mathrm{Nu}-3$. Naïve, saline treated. Female: 3 female mice treated with $\mathrm{Nu}-3$. Male: 3 male mice treated with $\mathrm{Nu}$ 3. SI: stimulation index. to the eye irritation scoring standard [12] at 1, 4, 24, 48, 72, and $96 \mathrm{~h}$ after administration, all of which were shown to be 0 . Therefore, according to the skin and eye irritation scoring standard, all the rats didn't show any toxic symptom after being given $\mathrm{Nu}-3$. The treated skins and eyes were normal compared to the controls.

3.5. CHO/HGPRT Mammalian Cell Mutagenesis. The mutation frequency was assessed based on the number of mutants per $1 \times 10^{6}$ clonable cells (Table 4$)$. In the activated assay, the mean mutation frequency was 3.3 for the saline negative control, 244 for the dimethylbenzanthracene positive control, 5.4 for the $500 \mu \mathrm{g} / \mathrm{ml}$ concentration of Nu-3; 4.5 for the $1000 \mu \mathrm{g} / \mathrm{ml}$ concentration of Nu-3 and 6.9 for the $2000 \mu \mathrm{g} / \mathrm{ml}$ concentration of $\mathrm{Nu}-3$. In the nonactivated assay, the mean mutation frequency was 3.3 for the saline negative control; 187 for the ethylmethanesulfonate positive control, 4.5 for the $500 \mu \mathrm{g} / \mathrm{ml}$ concentration of $\mathrm{Nu}-3,5.7$ for the $1000 \mu \mathrm{g} / \mathrm{ml}$ concentration of Nu-3 and 8.3 for the $2000 \mu \mathrm{g} / \mathrm{ml}$ concentration of $\mathrm{Nu}-3$. These data suggested that $\mathrm{Nu}-3$ was not mutagenic in the testing system both in the activated and 


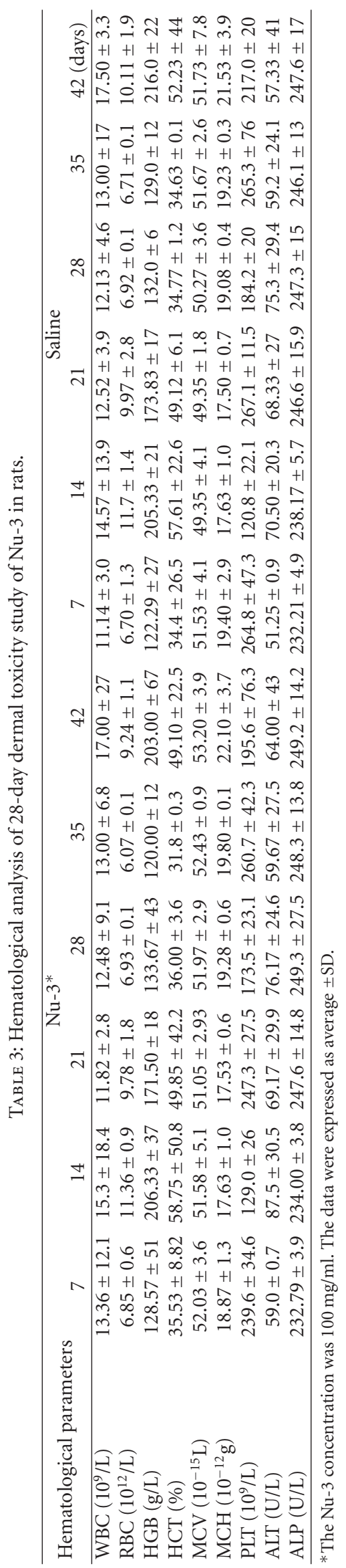




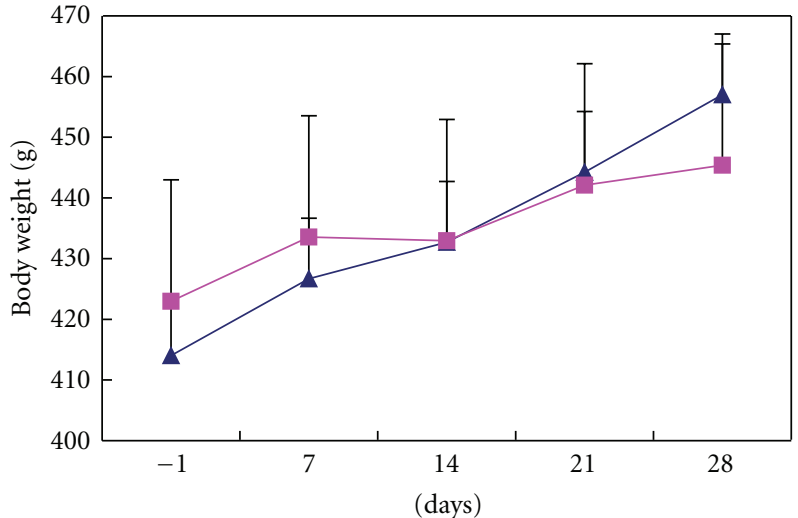

(a)

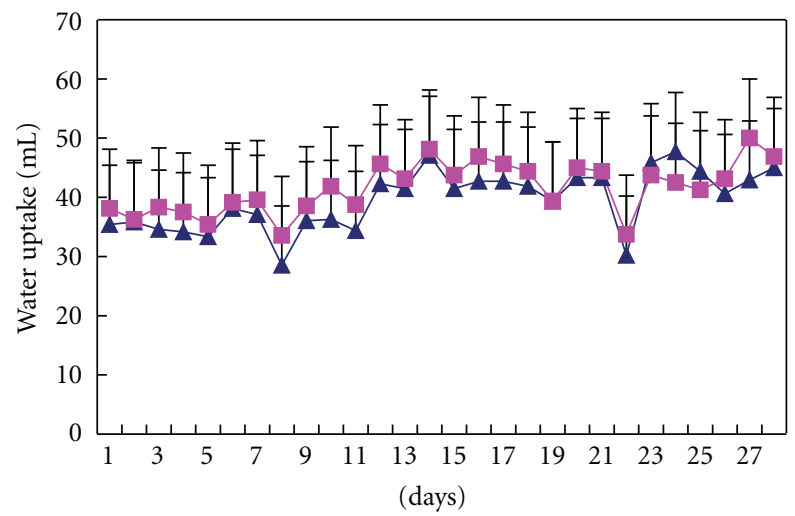

(b)

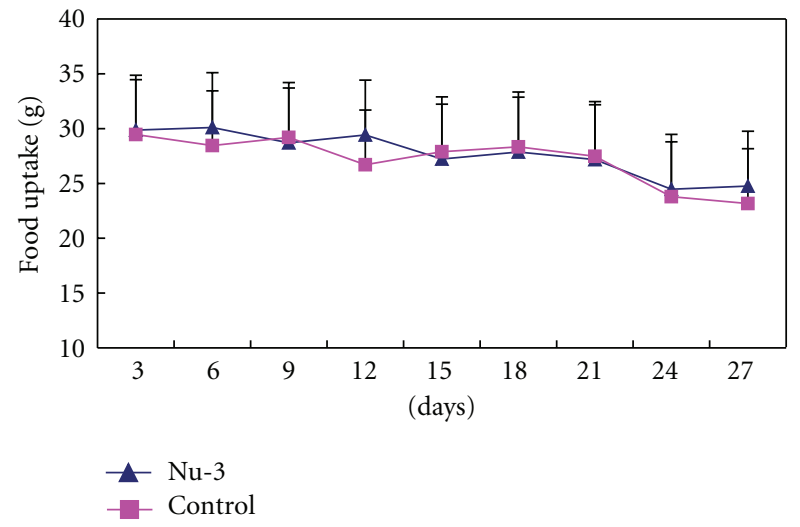

(c)

FIGURE 4: Clinical observations after repeated dermal doses of $\mathrm{Nu}-3$ for 28 days. (a) Body weight; (b) water uptake; (c) food uptake.

nonactivated assays in the dose range from $0-1000 \mu \mathrm{g} / \mathrm{ml}$. However, at a very high concentration $(2000 \mu \mathrm{g} / \mathrm{mL})$ there appeared to have an increase in mutation frequency, which suggested a weak positive response.

3.6. In Vivo Mouse Micronucleus Assay. The percentage of PCE and NCE of the erythrocytic lines in the Nu-3treated groups were not significantly different from that in the control group. The numbers of micronucleated PCE in all the groups were shown in Table 5. There was a
TABLE 4: CHO/HGPRT mutation assay.

\begin{tabular}{lcc}
\hline \multicolumn{3}{c}{ Mutation frequency (mutants $/ 1 \times 10^{6}$ clonable cells) } \\
Groups & Activated & Nonactivated \\
\hline Saline control & 3.30 & 3.30 \\
Positive control & 244.0 & 187.0 \\
$\mathrm{Nu}-3(500 \mu \mathrm{g} / \mathrm{ml})$ & 5.40 & 4.50 \\
$\mathrm{Nu}-3(1000 \mu \mathrm{g} / \mathrm{ml})$ & 4.50 & 5.70 \\
$\mathrm{Nu}-3(2000 \mu \mathrm{g} / \mathrm{ml})$ & 6.90 & 8.30 \\
\hline
\end{tabular}

significant difference in the numbers of micronucleated PCE between the positive control group and all Nu-3 treated groups $(P<.01)$ and between the high dosing group and the negative control $(P<.03)$. However, there was no significant difference between the two low-dosing groups and the negative control group $(P>.05)$. In all the test groups, the PCE numbers were almost same between the males and females. These results indicated that at low and medium dosages, $\mathrm{Nu}-3$ caused no evident cytotoxicity. At a very high dose $(1000 \mathrm{mg} / \mathrm{kg})$, an increase in the PCEs with absolute values outside the normal control levels (i.e., $0.3 \%-0.4 \%$ ) was observed, suggestive of a weak genotoxic potential for $\mathrm{Nu}-3$.

\section{Discussion}

Antibiotic drug development has failed to keep pace with the numbers of emerging antibiotic resistant strains and variants. Consequently, the past decade has seen the emergence of the widely publicized health crisis where the means to combat drug-resistant, plague bacteria and viral pandemics are failing. Thus, the healthcare community is desperate for new therapeutics. $\mathrm{Nu}-3$ is a novel small molecule and has been examined in several studies for its antibacterial and therapeutic action, showing that it was as effective as intravenously administered ciprofloxacin, a potent and broadspectrum fluoroquinolone [11]. However, there is still lack of toxicological data for Nubiotics. In this study, we reported that $\mathrm{Nu}-3$ is hypotoxical by intragastric administration. In the repeated dermal toxicity test, there was no chronic toxicity given by external application. The irritation study on cutis and mucosa revealed that Nu-3 did not irritate the skin tissue. Further studies demonstrated that $\mathrm{Nu}-3$ had no notable genetic toxicity both in vitro and in vivo. Taken together, our data suggested that $\mathrm{Nu}-3$ is a well tolerated and exhibited no toxicity when administrated via intragastric and topical routes.

Chemically, Nu-3 is a modified nucleotide, which could potentially cause genetic mutations in the target tissues through disrupting DNA or RNA replication/transcription. To examine if this is the case for $\mathrm{Nu}-3$, the golden standard assays in cells and animals were performed and found no meaningful mutational effect on the testing subjects. Three reasons may account for our observations. First, $\mathrm{Nu}-$ 3 is a modified thymidine (butyl-phosphate- $5^{\prime}$-thymidine$3^{\prime}$-phosphate-butyl). It is unlikely that $\mathrm{Nu}-3$ could compete with dTTP in the cellular environment to be incorporated 
TABLE 5: The numbers of micronucleated PCE of in vivo mouse micronucleus Assay.

\begin{tabular}{|c|c|c|c|c|c|c|c|}
\hline \multirow{2}{*}{ Groups } & \multirow{2}{*}{ Dose } & \multirow{2}{*}{ No. of Rats } & \multirow{2}{*}{$\begin{array}{l}\text { No. of } \\
\text { PEC/Rat }\end{array}$} & \multicolumn{2}{|c|}{$\sigma^{7}(5)$} & \multicolumn{2}{|c|}{$q(5)$} \\
\hline & & & & $\begin{array}{l}\text { No. of } \\
\text { micronucleated } \\
\text { PCE }\end{array}$ & $\begin{array}{l}\text { Rate* of } \\
\text { micronucleated } \\
\text { PCE (\%) }\end{array}$ & $\begin{array}{l}\text { No. of } \\
\text { micronucleated } \\
\text { PCE }\end{array}$ & $\begin{array}{l}\text { Rate of } \\
\text { micronucleated } \\
\text { PCE }(\%)\end{array}$ \\
\hline 1 & $1000 \mathrm{mg} / \mathrm{kg} \mathrm{Nu}-3$ & 10 & 2000 & $18 \pm 2.5$ & 0.9 & $20 \pm 0.5$ & 1.0 \\
\hline 2 & $500 \mathrm{mg} / \mathrm{kg} \mathrm{Nu}-3$ & 10 & 2000 & $8 \pm 0.5$ & 0.4 & $8 \pm 0.5$ & 0.4 \\
\hline 3 & $25 \mathrm{mg} / \mathrm{kg} \mathrm{Nu}-3$ & 10 & 2000 & $7 \pm 1.5$ & 0.35 & $8 \pm 0.5$ & 0.4 \\
\hline 4 & Saline & 10 & 2000 & $6 \pm 1.5$ & 0.3 & $7 \pm 0.5$ & 0.35 \\
\hline 5 & Cyclophosphamide & 10 & 2000 & $58 \pm 2.5$ & 2.9 & $60 \pm 0.5$ & 3.0 \\
\hline
\end{tabular}

* The rate was calculated with the number of polychromatic erythrocytes (PCEs) that contained at least one micronucleus divided by 2000.

into DNA during replication. Second, although the antibacterial activities of $\mathrm{Nu}-3$ have been demonstrated both in vitro and in vivo, its mechanism of action is still not clear. One of the possible mechanisms for Nu-3 action has recently been proposed, which was supported by the preliminary data showing that $\mathrm{Nu}-3$ caused significant changes of the membrane polarity. This change led to the disruption of the bacterial membrane. Lastly, the pharmacological data indicated that the bioavailability and PK profile of $\mathrm{Nu}-3$ were similar to those from other nucleoside drugs, which supports the notion of its hypotoxicity for pharmaceutical use (unpublished data). Thus, we suggest that the lack of genotoxicity of $\mathrm{Nu}-3$ observed in this study may be due to its unique feature of the mechanisms of action.

\section{Acknowledgment}

J. Sun and Y. Hu contributed to the work equally.

\section{References}

[1] M. M. Neuhauser, R. A. Weinstein, R. Rydman, L. H. Danziger, G. Karam, and J. P. Quinn, "Antibiotic resistance among gram-negative bacilli in US intensive care units: implications for fluoroquinolone use," Journal of the American Medical Association, vol. 289, no. 7, pp. 885-888, 2003.

[2] M. J. Richards, J. R. Edwards, D. H. Culver, and R. P. Gaynes, "Nosocomial infections in medical intensive care units in the United States: National Nosocomial Infections Surveillance System," Critical Care Medicine, vol. 27, no. 5, pp. 887-892, 1999.

[3] P. Richard, R. Le Floch, C. Chamoux, M. Pannier, E. Espaze, and H. Richet, "Pseudomonas aeruginosa outbreak in a burn unit: role of antimicrobials in the emergence of multiply resistant strains," Journal of Infectious Diseases, vol. 170, no. 2, pp. 377-383, 1994.

[4] C.-I. Kang, S.-H. Kim, H.-B. Kim et al., "Pseudomonas aeruginosa bacteremia: risk factors for mortality and influence of delayed receipt of effective antimicrobial therapy on clinical outcome," Clinical Infectious Diseases, vol. 37, no. 6, pp. 745751, 2003.

[5] O. Piazza, A. Iasiello, C. Papaianni et al., "Incidence of antimicrobial-resistant ventilator associated pneumonia: an eighteen-month survey," Panminerva Medica, vol. 47, no. 4, pp. 265-267, 2005.
[6] C. Llanes, C. Neuwirth, F. El Garch, D. Hocquet, and P. Plésiat, "Genetic analysis of a multiresistant strain of Pseudomonas aeruginosa producing PER-1 $\beta$-lactamase," Clinical Microbiology and Infection, vol. 12, no. 3, pp. 270-278, 2006.

[7] S. A. Murray and D. R. Snydman, "Investigation of an epidemic of multi-drug resistant Pseudomonas aeruginosa," Infection Control, vol. 3, no. 6, pp. 456-460, 1982.

[8] L. Pagani, C. Colinon, R. Migliavacca et al., "Nosocomial outbreak caused by multidrug-resistant Pseudomonas aeruginosa producing IMP-13 metallo- $\beta$-lactamase," Journal of Clinical Microbiology, vol. 43, no. 8, pp. 3824-3828, 2005.

[9] J.-P. Pirnay, D. De Vos, C. Cochez et al., "Molecular epidemiology of Pseudomonas aeruginosa colonization in a burn unit: persistence of a multidrug-resistant clone and a silver sulfadiazine-resistant clone," Journal of Clinical Microbiology, vol. 41, no. 3, pp. 1192-1202, 2003.

[10] R. Bax, N. Mullan, and J. Verhoef, "The millennium bugs—-the need for and development of new antibacterials," International Journal of Antimicrobial Agents, vol. 16, no. 1, pp. 51-59, 2000.

[11] R. M. K. Dale, G. Schnell, and J. P. Wong, "Therapeutic efficacy of "nubiotics" against burn wound infection by Pseudomonas aeruginosa," Antimicrobial Agents and Chemotherapy, vol. 48, no. 8, pp. 2918-2923, 2004.

[12] B. J. Yuan, M. Y. Liao, and B. Li, Drug Toxicological Methods and Techniques, Chemical Industry Publisher, Beijing, China, 1st edition, 2007.

[13] J. P. O’Neill and A. W. Hsie, "Phenotypic expression time of mutagen induced 6-thioguanine resistance in Chinese hamster ovary cells (CHO/HGPRT system)," Mutation Research, vol. 59, no. 1, pp. 109-118, 1979.

[14] J. P. O’Neill, P. A. Brimer, R. Machanoff, G. P. Hirsch, and A. W. Hsie, "A quantitative assay of mutation induction at the hypoxanthine-guanine phosphoribosyl transferase locus in Chinese hamster ovary cells (CHO/HGPRT system): development and definition of the system," Mutation Research, vol. 45, no. 1, pp. 91-101, 1977.

[15] J. P. O’Neill, R. Machanoff, J. R. San Sebastian, and A. W. Hsie, "Cytotoxicity and mutagenicity of dimethylnitrosamine in mammalian cells (CHO/HGPRT system): enhancement by calcium phosphate," Environmental Mutagenesis, vol. 4, no. 1, pp. 7-18, 1982.

[16] M. Hayashi, R. R. Tice, J. T. MacGregor et al., "In vivo rodent erythrocyte micronucleus assay," Mutation Research, vol. 312, no. 3, pp. 293-304, 1994. 

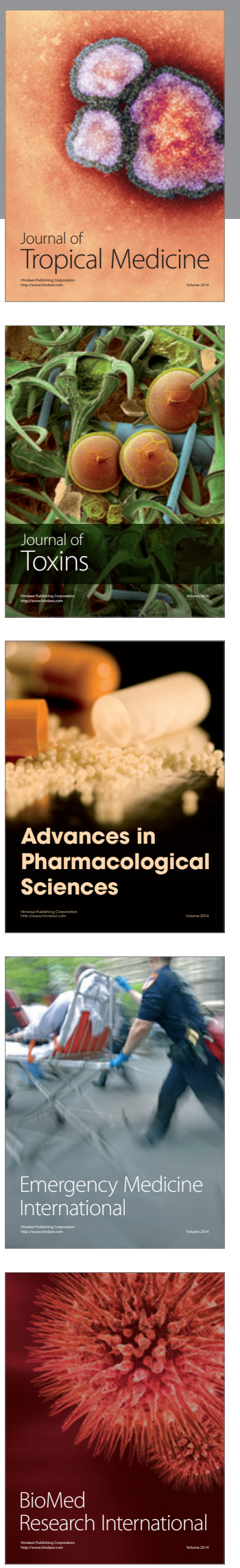
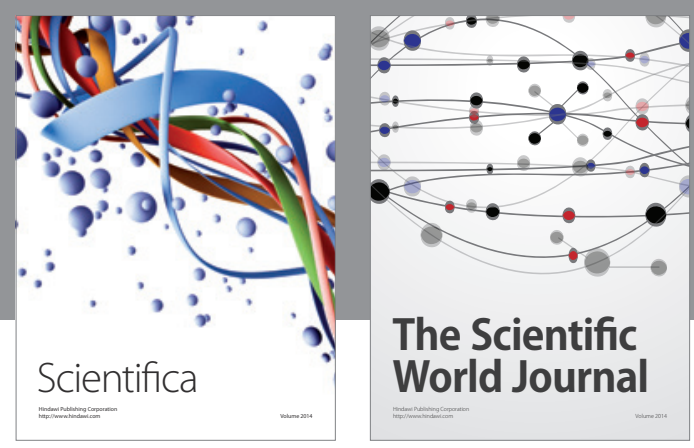

The Scientific World Journal
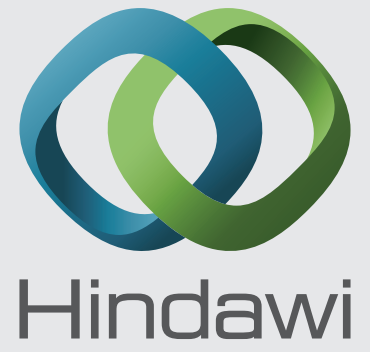

Submit your manuscripts at

http://www.hindawi.com
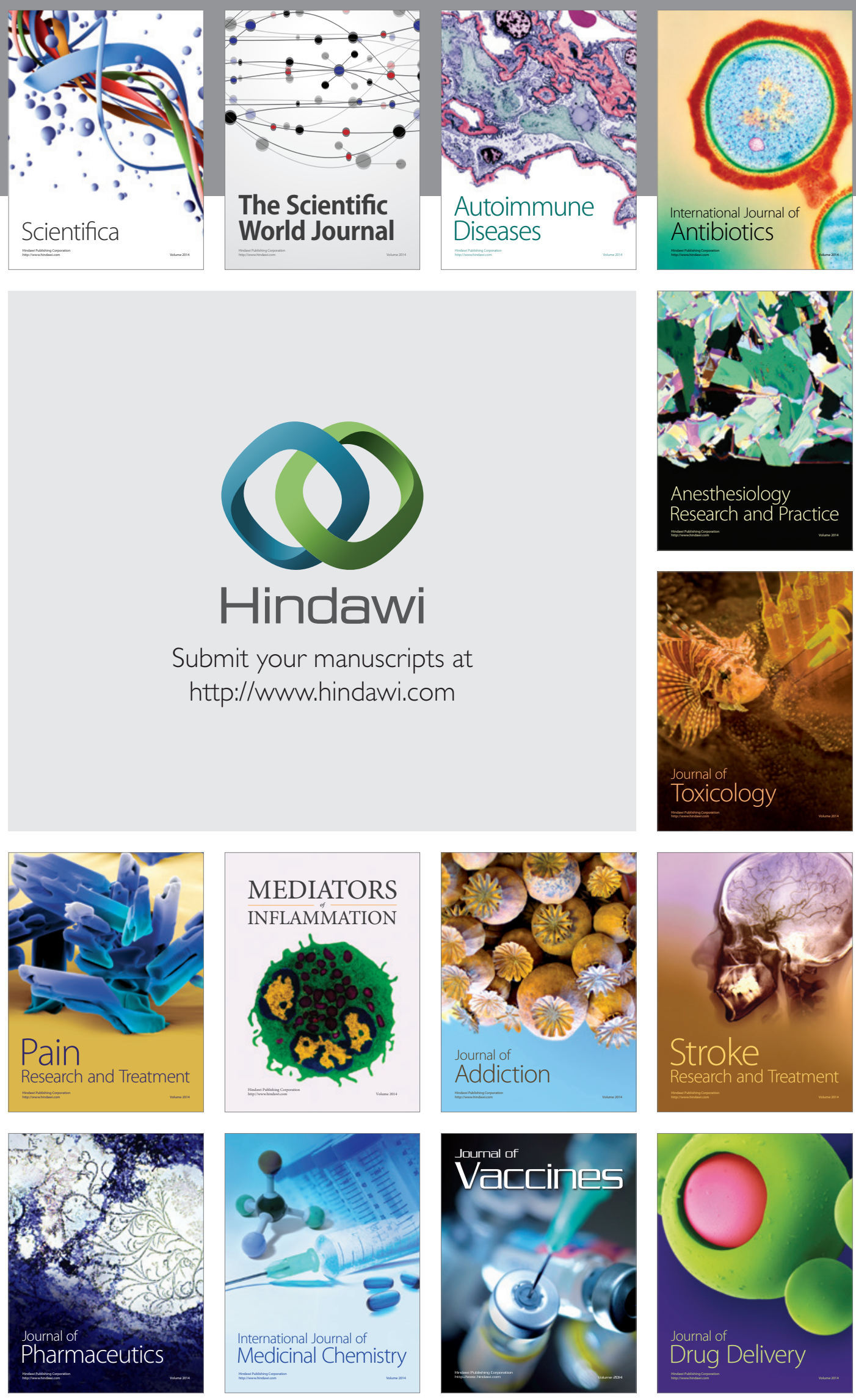